volume of the reacted material is normally less than the starting volume of the reactants. The overall strain accepted by the gold tube is therefore very considerable, and considerable deformation occurs to the capsule after a chemical reaction under high pressure.

These capsules have been tested to an internal pressure of 15 bar without rupture and may be used for some low boiling liquids, although for liquids having a vapour pressure of more than 2 bar at room temperature it is the practice to use $0.25 \mathrm{~mm}$ wall thickness gold tubing with 5 per cent nickel-gold solid ends brazed in as plugs, one end carrying a $1 \mathrm{~mm}$ bore $2 \mathrm{~mm}$ OD nickel filling tube. This nickel tube is attached to a vacuum line and the material to be pressed is vacuum-distilled into the capsule through the nickel tube. When the capsule is full, it is sealed by cold pinch-welding the nickel tube and finally "pinching-off" from the vacuum line.

The third type of capsule in use is much simpler but quite leak-tight and suitable for exploratory experiments requiring samples up to about $0.5 \mathrm{~g}$. For this, a 2 to $3 \mathrm{~cm}$ length of $5 \mathrm{~mm} \mathrm{OD} \times 0.1 \mathrm{~mm}$ wall thickness gold tubing is pinched flat at one end for about $5 \mathrm{~mm}$, folded over, and the fold covered by a small piece of $0.1 \mathrm{~mm}$ gold sheet. This is then placed in a slot in a short length of $3 \times 3 \mathrm{~mm}$ mild steel bar which is crushed in a vice on to the folded gold tube. After filling, the other end of the tube is treated in the same way.

The advantages of gold over other materials for the construction of these capsules have been (a) the workability, enabling spinning and clamping of the ends of the tube to be easily effected; $(b)$ the inertness of gold to most chemicals; $(c)$ the high melting-point of gold, enabling the product to be contained within the capsule should an exothermic reaction take place leading to an excessive temperature; $(d)$ the ductility and low shear yield stress allowing the large volume change of the capsule contents to be accommodated and giving a low pressure differential between the pressure transmitting fluid and the capsule contents; (e) the high reclaim value of the used gold tubing keeps the cost of each capsule to a reasonable figure.

The work described in this note forms part of the research programme of the High Pressure Section, Division of programme of the High Pressure Section, Division of
Inorganic and Metallic Structure, National Physical Laboratory.

\section{References}

1 H. S. Turner, W. F. Wall and S. L. S. Thomas, Nat. Phys. Lab. Report I.M.S. 16 (June 1972)

2 M. S. Paterson, f. Sci. Instrum., 1962, 39, 173

3 R. K. Bartlett, G. O'Neill, N. G. Saville, S. L. S. Thomas and W. F. Wall, Br, Polymer. F., 1970, 2, 225

\title{
Diffusion Behaviour of Copper and Gold
}

The sequential deposition of metallic thin films has become accepted as a perfectly routine procedure in the manufacture of microelectronic components. However, in terms of thermal stability, composite films of this nature must be considered as planar diffusion couples of exceptional thinness, with behaviour unfortunately differing considerably from that of bulk samples. As component reliability is of prime importance, it becomes necessary to learn as much as possible about the diffusion behaviour of thin films and, with this in mind, two investigators at I.B.M. undertook a quantitative study of interdiffusion between copper and gold (1).

Samples for investigation were prepared by the consecutive evaporation of each of these metals on to fused quartz substrates. They were subsequently examined by X-ray diffractometry both before and after annealing operations at various accurately controlled temperatures between 160 and $220^{\circ} \mathrm{C}$, for periods of up to 500 hours.

Previous work on bimetallic couples and, indeed, classical theory suggest that all phases in the diagram should appear in the annealed couples, though not necessarily all at the same time. Curiously enough only two new phases, $\mathrm{Cu}_{3} \mathrm{Au}$ and $\mathrm{CuAu}_{3}$, were found-the other possible ordered phase, $\mathrm{CuAu}$, being conspicuously absent. This perplexing observation was additionally confirmed by normal metallographic techniques which showed the annealed couple to have a layered structure of $\mathrm{Cu} / \mathrm{Cu}_{3} \mathrm{Au} / \mathrm{CuAu}_{3} / \mathrm{Au}$ with abrupt steps in composition between the different phases.

The absence of $\mathrm{CuAu}$ is something of an enigma, and the lack of any form of concentration gradient in the terminal metals is contrary to the established laws of intermetallic diffusion, and indeed has already evoked comment to this effect (2).

Furthermore, it is equally curious that $\mathrm{CuAu}_{3}$ appears as a separate layer, since its critical temperature for disordering is $200^{\circ} \mathrm{C}$, which lies well inside the upper temperature limit set for this experiment.

Nevertheless, although results show the growth of both $\mathrm{Cu}_{3} \mathrm{Au}$ and $\mathrm{CuAu}_{3}$ to be linear and their thickening rates identical, the rate is much too rapid to be due to volume diffusion and much too slow to be due to grain boundary diffusion. Logically, it may be concluded that if the growth rate is not governed by the rate of diffusion of copper and gold through the ordered layers, it must be some function of atomic movements at the interface, acting in such a way as to ensure both the correct order and stoichiometry. It thus begins to seem quite probable that formation of a $\mathrm{CuAu}$ layer was, in any case, impossible in the situation described.

A. D. M. K.

\section{References}

1 K. N. Tu and B. S. Berry, F. Appl. Phys, , 1972, 43, (8), 3283-3290

2 Nature Physical Science, 1972, 239, (91), 50 